\section{A relação entre o tempo e a linguagem em "A portrait of the artist as a young man ${ }^{n_{1}}$}

The relation between time and language in "A portrait of the artist as a young man"

$\overline{1}$ O presente artigo foi desenvolvido a partir de uma pesquisa realizada no mestrado, referenciada em Mendonça Junior (2018).

\section{Jorge Witt de Mendonça Junior (D) 9}

witt.junior@gmail.com

Universidade Federal do Rio Grande do Norte - UFRN

\section{Rosanne Bezerra de Araujo (D) 9}

rosanne.araujo@terra.com.br

Universidade Federal do Rio Grande do Norte - UFRN

\section{Resumo}

A obra analisada narra a história de Stephen Dedalus. A partir da perspectiva do desenvolvimento do personagem, propomos um estudo do romance enquanto gênero diferenciado no tratamento do tempo. Nosso objetivo é analisar como a linguagem cria uma camada para o desenvolvimento do personagem na estrutura temporal da obra, possibilitando o compartilhamento de uma experiência temporal pela linguagem. Por meio da comparação de trechos recortados do primeiro e do último capítulo, concluímos que para configurar o tempo na linguagem, o autor utiliza de recursos como os diálogos para desenvolver um "presente fictício" e modificações na linguagem representada dos personagens para criar uma atmosfera infantil e uma linguagem poética para Stephen. Assim, nos aproximamos de forma mais precisa da realidade da obra por meio de impressões subjetivas do personagem em diferentes momentos de sua vida - a saber, o desenvolvimento da narrativa da vida de Stephen segue pelo tempo em uma camada representada na própria estrutura linguística da obra.

\section{Palavras-chave}

Romance; Tempo; Linguagem; Personagem; James Joyce.

\section{Abstract}

The analyzed work narrates the story of Stephen Dedalus. From the perspective of the character's evolution, we propose a study of the novel as a differentiated genre in the literary treatment of time. Our aim is to analyze how language creates a layer for the character's development in the temporal structure of the book, enabling the sharing of a temporal experience through time. By comparing parts of the first and the last chapter of the novel, we conclude that to configure time in the language, the author used sources like the dialogue to develop a "fictional present" and modifications in the represented language of the characters to create a childlike atmosphere and a poetic language for Stephen. Therefore, we approach more precisely the reality of the novel through subjective impressions of the character in different moments of his life. The development of Stephen's life narrative proceeds through time in a represented layer in the very linguistic structure of the novel.

\section{Keywords}

Novel; Time; Language; Character; James Joyce.

\section{Linguagęm Foco}

Revista do Programa de Pós-Graduação em Linguistica Aplicada da UECE

FLUXO DA SUBMISSÃO

Submissão do trabalho: $19 / 10 / 2020$

Aprovação do trabalho: 22/11/2020

Publicação do trabalho: 22/01/2021

\section{COMO CITAR}

MENDONÇA JUNIOR, Jorge Witt de; ARAUJO, Rosanne Bezerra de. A relação entre o tempo e a linguagem em "A portrait of the artist as a young man". Revista Linguagem em Foco, v.12, n.3, 2020. p. 110-129. Disponível em: https://revistas.uece.br/index.php/linguagememfoco/article/view/4232.
Distribuído sob

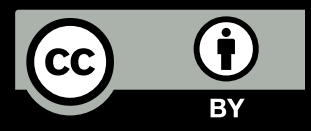




\section{Introdução}

O romance A portrait of the artist as a young man, escrito pelo autor irlandês James Joyce, foi publicado de forma integral em 1916. A obra narra a vida do personagem Stephen Dedalus desde a sua infância até o início da idade adulta. Para nossa pesquisa, nos propomos a analisar a estrutura temporal da obra no que diz respeito a questão da linguagem, ou seja, de que forma a passagem do tempo e o desenvolvimento do personagem relacionam-se com a estrutura linguística do romance.

Um dos maiores méritos de Joyce na composição do seu retrato seria o controle linguístico dos estilos aplicados à obra de uma forma que podemos perceber que o personagem cresce a partir da adaptação da linguagem a cada uma das etapas do seu crescimento. No primeiro capítulo, temos uma amostra da vivência infantil de Stephen, sua época de criança tanto na escola como na volta para casa. Conhecemos, por exemplo, os conflitos enfrentados com os outros estudantes. No segundo capítulo, temos os acontecimentos que introduzem o personagem à adolescência: como a descoberta do sentimento por uma menina (ele compõe poemas para ela) e os seus interesses já envolvem uma temática mais madura do que o capítulo anterior - introduzindo também a questão da descoberta da sexualidade. Como Stephen já está em uma idade mais avançada a partir desse ponto, a forma da narrativa o permite que desenvolva seu discurso próprio, com a utilização do discurso direto. Assim, temos acesso à voz do próprio Stephen com uma frequência maior do que nos capítulos anteriores. A partir do terceiro capítulo, já podemos notar de forma mais explícita um avanço de complexidade na linguagem, tornando se mais abstrata ao tratar de temáticas como o medo do pecado e a relação do personagem com a religião. Se o terceiro capítulo é marcado pelo encontro com a temática religiosa pelo castigo, o quarto capítulo marca-se pela tentativa de dedicação absoluta à religião, a recorrência da dúvida e, finalmente, a inspiração e epifania de uma nova descoberta - o caminho do artista. O quinto e último capítulo do romance é, principalmente, composto pelas ideias de Stephen sobre estética, além das suas conversas na universidade e sua última declaração de independência. Neste capítulo, Stephen, e consequentemente a linguagem que o acompanha, alcança o último nível de sua reflexão.

Observando esse breve resumo da obra, é possível notar como o desenvolvimento do personagem está intrinsecamente ligada a evolução da lingua- 
gem da obra. Ou seja, à medida que Stephen cresce, a linguagem narrativa do romance (em grande parte, empreendida por um narrador em terceira pessoa) também avança. É justamente nesse ponto que construímos nosso argumento por meio do qual o tempo da obra em questão além de passar por meio de muitas marcações narrativas exploradas no texto, passa também pela camada linguística da obra - como analisaremos neste artigo.

Para nossa pesquisa, utilizaremos o apoio teórico de autores como Bakhtin (2010) e Lukács (2007) para discutir a questão teórica do tempo no romance. Além da contribuição de Genette (1995), Mendilow (1972), Candido (2007), Ricoeur (1995), Rosenfeld (1996), Auerbach (2002) entre outros autores por meio dos quais exploraremos a narrativa da obra em questão. Ao desenvolvermos o suporte teórico para a nossa pesquisa, optamos pela utilização de autores de campos epistemológicos diferentes, tendo como objetivo sua aproximação e colaboração. Levando em consideração, por exemplo, que teóricos tais como Genette (1995) ou Mendilow (1972) apresentam uma proposta mais estruturalista, e que autores como Bakhtin (2010) ou Lukács (2007)' dedicam a sua atenção também à questão social da análise, nosso trabalho busca promover um recorte da teoria desses autores em uma cooperação analítica. Como nos lembra Bakhtin (2017, p. 28), "quanto mais delimitação, melhor, desde que sejam delimitações benevolentes. Sem brigas na linha de delimitação. Cooperação". Nosso texto, por questões de delimitação, utilizará autores que consideram tanto a questão social da linguagem como sua estrutura, no entanto, daremos foco ao eixo estrutural-linguístico da obra analizada - com a possibilidade de uma futura expansão da pesquisa em uma abordagem social.

No recorte de nossa análise, optamos por selecionar trechos do romance em questão que fossem capazes, ao serem comparados, de expressar a passagem do tempo ao longo da narrativa e principalmente sua relação com a linguagem da obra. Dessa forma, analisamos trechos referentes ao primeiro e ao último

1 Apesar de ser possível aproximar os autores Bakhtin (2010) e Lukács (2007) pela questão social da análise literária, é importante mencionar que os dois autores também podem divergir em alguns pontos centrais de suas respectivas teorias. Por exemplo, Bakhtin (2010, p. 397) considera o romance um gênero "por se constituir, e ainda inacabado". Lukács, por sua vez, apresenta perspectivas relativamente diferentes em momentos diferentes da sua obra. Em seu ensaio "O romance como epopeia burguesa", por exemplo, mais tardio em sua produção intelectual, o autor está mais próximo do referencial teórico de autores como Marx Engels, enquanto em "A teoria do romance", Lukács (2007) aproxima-se mais de uma base filosófica de transição entre autores como Kant e Hegel. Para nossa pesquisa, consideramos a aproximação de Bakhtin (2010) com a perspectiva de Lukács (2007) - em "A teoria do romance", obra que optamos por utilizar em nosso texto. Para um entendimento mais aprofundado das diferentes fases de Lukács e sua relação com o romance, temática que não cabe em nossa pesquisa, ver Gallo (2012). 
capítulo de A portrait of the artist as a young man, porém, antes disso, achamos necessário abordar a relação entre romance e tempo. Dessa forma, apresentamos um capítulo de abordagem teórica sobre o gênero da obra em questão, relacionando-o com a perspectiva do tempo em literatura. Posteriormente, apresentamos a análise da obra, dando foco a sua estrutura e as questões temporais da narrativa.

\section{O gênero romanesco e sua relação com o tempo na literatura}

A discussão sobre o gênero romance possui uma forte tendência a desenvolver-se a partir da sua abordagem de comparação com o referencial de gênero historicamente anterior ao romance, isto é, a poesia épica². Essa comparação é válida, sobretudo, no que diz respeito ao aspecto do tempo, tratando-se do ponto em que a mudança transcorrida entre as duas realidades literárias se deu de forma mais consistente. A fim de explicar essa mudança, faremos menção à realidade social que assistiu à produção do gênero épico e presenciou a sua transição para o romance, partindo da noção de que as mudanças que ocorrem na realidade social refletem-se na realidade literária. Para essa abordagem, consideraremos principalmente as ideias de Lukács (2007) e Bakhtin (2010), entre outros autores como Genette (1995) e Mendilow (1972), propondo uma aproximação de autores de base epistemológica diferentes, como mencionado anteriormente, delimitando o foco em uma análise mais estrutural da obra.

Uma das principais mudanças ocorridas na transição histórica da narrativa épica para a ficção romanesca foi aquela referente à orientação temporal desenvolvida pela passagem de um gênero ao outro. Benjamin (2011, p. 211) nos fala da musa da epopeia como sendo a memória, isto é, "Mnemosyne, a deusa da reminiscência". A importância da memória na forma épica está diretamente relacionada à sua conexão e orientação para o passado. A forma do romance, por sua vez, não comporta em sua estrutura o mesmo referencial de tempo da épica; isto é, em linhas gerais, a narrativa romanesca está diretamente orientada ao presente. O plano temporal no qual estava inserida a epopeia, enquanto gênero,

2 A título de esclarecimento, segundo Moises (2004, p. 153), "A poesia épica deve girar em torno de assunto ilustre, sublime, solene, especialmente vinculado a cometimentos bélicos; deve prender-se a acontecimentos históricos, ocorridos há muito tempo, para que o lendário se forme ou/e permita que o poeta Ihes acrescente com liberdade o produto da sua fantasia; o protagonista da ação há de ser um herói de superior força física e mental [...], instintivo, natural; o amor pode inserir-se na trama heroica, mas em forma de episódios isolados; e, sendo terno e magnânimo, complementar harmonicamente as façanhas de guerra". 
não coincide com aquele habitado pelo público que consumia esse tipo de literatura. Os valores que compunham a epopeia possuíam como referência temporal o passado; e isto fazia com que o público não necessariamente se reconhecesse nos significados dessa narrativa. Os respectivos referenciais de tempo, do gênero e do público, não coincidiam. O romance, por sua vez, é estruturado a partir de um plano temporal que está em sincronia com o seu público. Os valores que o determinam são os mesmos valores que regem a sociedade que o consome.

No processo dessa transição de um gênero a outro, a mudança de orientação temporal, do passado para o presente, provocou no romance uma inclinação à maleabilidade formal típica de um gênero não totalmente consolidado. Essa mudança provoca no romance uma variação de possibilidades que não se aplicam à epopeia justamente pela sua falta de um referencial de tempo atualizado, localizado no presente e passível de mudança e flexibilidade formal. "O deslocamento do centro temporal da orientação literária permite ao autor, sob todas as suas máscaras e aspectos, mover-se livremente no campo do mundo que é representado, o qual, na epopeia, era absolutamente inacessível e fechado" (BAKHTIN, 2010, p. 417). A sua conexão com o presente garantiu ao romance uma postura mais consciente de suas possibilidades, sobretudo em relação à experiência temporal, garantindo que se tornasse um gênero autocrítico, sempre em andamento, como o tempo presente. De acordo com Bakhtin (2010, p. 400), "esse caráter autocrítico do romance é o seu traço notável como gênero em formação". A especificidade do gênero romanesco em relação ao tempo, portanto, mostra-se na sua orientação temporal; ser constituído a partir de uma forma voltada ao presente obriga o romance a viver a experiência temporal de forma intensa, diluída na sua própria estrutura.

Lukács (2007) refere-se ao processo de transição entre a epopeia e o romance como um efeito das mudanças que se davam no seu contexto histórico-filosófico. Passava-se de um mundo "integrado" para um mundo marcado pela separação e distância. A substância épica, por exemplo, difere-se da matéria romanesca no que cabe a sua relação com a transcendência. "O romance é a epopeia de uma era para a qual a totalidade extensiva da vida não é mais dada de modo evidente, para a qual a imanência do sentido à vida tornou-se problemática" (LUKÁCS, 2007, p. 55). Se considerarmos que a realidade social que servia de apoio ao desenvolvimento do gênero épico é marcada pela integração transcendental do homem e a sua própria essência na vida, percebemos que a característica central da epopeia é justamente solidificar-se em um ambiente 
no qual o homem e o seu lugar na natureza eram indissociáveis. Ou seja, entre o homem e o papel que desempenha em sua existência não há distância, não há problematização. Essa integração do homem é algo inerente, um aspecto que compõe sua a realidade como um todo. "A feliz totalidade existente da vida está subordinada ao verso épico segundo uma harmonia preestabelecida: o próprio processo pré-literário de uma abrangência mitológica de toda a vida" (LUKÁCS, 2007, p. 57). O romance, por sua vez, nasce sob o signo da fragmentação, da perda da totalidade inerente. Uma vez separados, humanidade e a imanência de sentido, a progressiva problematização do seu lugar no mundo levou o homem a desenvolver um contexto histórico-filosófico no qual o romance iria consolidar-se como uma forma mais apropriada que a poesia épica. Até então, o mundo não era visto pelo prisma da sua contingência, e não havia necessidade nem espaço para uma problematização filosófica, a distância metafísica imposta ao homem o obrigou a enxergar o mundo através de uma nova forma. O gênero romanesco nasce em um tempo de mudanças, tanto de ordem social como filosófica. Bakhtin (2010, p. 427) o descreve como um gênero que "desde o início se constituiu e se desenvolveu no solo de uma nova sensibilidade em relação ao tempo". Essa sensibilidade, propiciada pela sua constituição consciente e autocrítica, assistiu a todas as suas etapas históricas, como nos lembra Moretti (2007, p. 310) sintetizando a trajetória do gênero como "sua gênese no século XVIII, seu sucesso no século XIX e sua problematização no século XX". Considerando que, no geral, o gênero romanesco possuiu uma especificidade voltada ao tempo, no romance moderno, a problematização da sua forma gerou uma intensa preocupação em diluir a experiência temporal dentro da sua própria estrutura. Uma preocupação geral, vivenciada pela arte moderna como um todo, isto é, o sujeito que vive a narrativa diluída no tempo não pode ser reconhecido "apenas tematicamente, através de uma alegoria pictórica ou a afirmação teórica de uma personagem de romance, mas através da assimilação dessa relatividade à própria estrutura da obra de arte" (ROSENFELD, 1996, p. 81). No que diz respeito especificamente ao problema do tempo e da sua vivência, as ideias de Mendilow, em seu livro 0 tempo e o romance (1972, p. 6), apontam para uma mudança de ordem social que influencia a realidade literária. Citando alguns dos fatores que ajudaram a determinar essa mudança, ele afirma que eles "retiraram do homem aquele sentimento de estaticidade social, aquela certeza de permanência que parece ter marcado períodos de transformação mais confiantes e vagarosos". Essa perda da sensação de equilíbrio social coincide com a descrição, metafísica, de Lukács (2007, p. 38) da forma do romance como sendo "uma expressão do desabrigo 
transcendental". Essa perda do estável, do consolidado, do acabado, do referencial de transcendência, quando refletida na literatura, foi responsável pela flexibilidade formal do romance, totalmente impraticável tanto na época, quanto na forma fixa, da poesia épica. No instante em que a sociedade passou a viver o tempo de forma diferenciada, a literatura incorporou essa experiência dentro da sua estrutura. Sendo o tempo um aspecto tão determinante no romance, ele não escaparia aos cuidados dos romancistas, bem como dos teóricos, no processo de compreensão da arte romanesca. Lukács (2007, p. 129) afirma que "[...] quase se pode dizer que toda a ação interna do romance não passa de uma luta contra o poder do tempo". Essa determinação decorre do fato de que, uma vez aberto o horizonte de experimentações formais, o tempo passou a integrar a realidade na vida (que até então orientava-se para um passado estático). Estar consciente da própria experiência temporal fez o romance conectar-se com o seu tempo, aproximando-se do leitor e aprimorando as formas de falar com ele, já que pertenciam ao mesmo plano temporal de realidade. Segundo Mendilow (1972, p. 19), "não há razão, pois, para admirar-se que romancistas, não apenas de hoje, mas de todas as épocas, devessem ocupar-se com vários aspectos do tempo, quando a maioria das convenções e técnicas da ficção estão ligadas a ele". Partindo da intrínseca relação que se desenvolve do romance com o tempo, e a preocupação específica do romance moderno em problematizar essa relação na sua forma, a questão da linguagem do romance ganha uma conotação que também engloba o tempo, uma vez que a forma literária é composta também de natureza linguística. O tempo avança na literatura de forma análoga à maneira como avança na vida; é o seu meio de progredir, a natureza material do seu processo, que se diferencia entre a vida e a literatura. A narrativa literária possui em si uma estrutura temporal própria. Podemos afirmar, de acordo com Genette (1995, p. 31),

A narrativa é uma sequência duas vezes temporal...: há o tempo da coisa-contada e o tempo da narrativa (tempo do significado e tempo do significante). Não só é esta dualidade aquilo que torna possíveis todas as distorções temporais de que é banal dar conta nas narrativas (três anos na vida do herói resumidos em duas frases de um romance, ou em alguns planos de uma montagem frequentativa de cinema, etc.); mais fundamentalmente, convida-nos a constatar que uma das funções da narrativa é cambiar um tempo num outro tempo. (GENETTE, 1995, p.31)

Para a nossa proposta, tomamos como objetivo a realidade literária do tempo, suas ferramentas específicas e coerentes com o seu meio, considerando, 
portanto, que a sua realidade é feita de linguagem. Para experimentar a experiência temporal da vida, no meio formal e literário do romance, é preciso trazer os aspectos de um plano ao outro, da vida para a literatura, e transformar uma experiência em outra por meio de um processo que exige do autor o domínio da linguagem, que é o material da literatura. Sobre a estrutura que compõe a realidade literária do romance, Candido (2007, p. 54) afirma:

Os três elementos centrais dum desenvolvimento novelístico (o enredo e a perso-
nagem, que representam sua matéria; as ideias, que representam o seu significa-
do, - e que são no conjunto elaborados pela técnica), estes três elementos só exis-
tem intimamente ligados, inseparáveis, nos romances bem realizados. No meio
deles, avulta a personagem, que representa a possibilidade de adesão afetiva e
intelectual do leitor, pelos mecanismos de identificação, projeção e transferência
etc. A personagem vive o enredo e as ideias, e os torna vivos. (CÂNDIDO, 2007, p. 54)

Essa interdependência entre os elementos do romance é um pré-requisito para a sua coerência e integralidade; é uma forma que o romance dispõe de trazer aspectos da realidade para dentro da sua composição, redirecionando-os, dando origem a outra realidade, literária, em todos os aspectos, presente no texto. Esse procedimento ocorre da mesma forma com a recriação da experiência temporal. Nesse processo de recriação, deparamo-nos com aquilo que Ricoeur (1995) descreve, em sua análise do romance de Virginia Woolf, Mrs. Dalloway, como uma "experiência do tempo". Em sua obra Tempo e Narrativa II, Ricoeur (1995) desenvolve um capítulo, sobre a obra de Wolf, chamado "A experiência temporal fictícia", propondo que a narrativa é responsável por reconfigurar a experiência temporal dos personagens através da sua estrutura, reorganizando o tempo de modo a criar uma experiência análoga àquela que sentimos com a passagem do tempo. Ricoeur (1995) relaciona a maneira como a narrativa é organizada na linguagem do romance com a maneira como o tempo se organiza na narrativa, encerrando esse processo de configuração da narrativa e reconfiguração do tempo unicamente na instância do tempo. De acordo com a sua proposta:

\footnotetext{
Abrimos o campo para uma investigação que faz confinar os problemas de configuração narrativa com os de reconfiguração do tempo na narrativa. Todavia, essa investigação não irá ultrapassar, no momento, o limiar que conduz da primeira à segunda problemática, na medida em que a experiência do tempo em questão aqui é uma experiência fictícia cujo horizonte é um mundo imaginário, que continua sendo o mundo do texto (RICOEUR, 1995, p. 181).
}

A maneira como os elementos essenciais do romance se integram a fim de criar a experiência fictícia do tempo, isto é, uma experiência literária que car- 
rega traços daquilo que sentimos na realidade, determina a força da narrativa, nessa e em qualquer outra categoria literária. A recriação dessa experiência dá-se através das ferramentas literárias de que dispõe o autor. Ele precisa sugerir, metonimicamente, o todo que encontramos na vida a partir das partes que ele domina na literatura. Bem como nos lembra Candido (2007, p. 59), "a força das grandes personagens vem do fato de que o sentimento que temos da sua complexidade é máximo; mas isso, devido à unidade, à simplificação estrutural que o romancista Ihe deu". É por meio de recursos, instrumentos, literários como o personagem, por exemplo, que podemos sentir a experiência modulada no romance de forma a carregar essas impressões, o delineamento, do que passamos na vida. O nível de complexidade desenvolvido pelo escritor para trazer a realidade para dentro da obra, especificamente na questão do tempo, no romance moderno, coincide com aquela preocupação em diluir, em assimilar, a experiência temporal na estrutura da narrativa enquanto uma tendência da arte moderna. Essa preocupação típica do romance do século XX é discutida e exemplificada por Auerbach (2002, p. 481), ao tratar das técnicas aplicadas por Virginia Woolf na sua narrativa To the lighthouse; segundo ele, "o escritor, como narrador de fatos objetivos, desaparece quase que completamente; quase tudo o que é dito aparece como reflexo na consciência das personagens do romance". Percebemos, portanto, com esse procedimento, que a distância relativa entre o personagem e o narrador também passa a ser problematizada no romance moderno. O desaparecimento do escritor indica, na verdade, uma aproximação entre aquele que narra e aquele que é narrado. Uma vez que o discurso chega até o leitor através de um contato mais intenso diretamente com a consciência do personagem, o distanciamento que a posição do narrador imprime por não estar, de fato, presente nos acontecimentos diminui e o procedimento atinge um nível de realismo mais agudo, tratando não das impressões de um narrador terceiro sobre o personagem, mas do próprio reflexo da sua consciência. Utilizaremos esse procedimento apontado por Auerbach (2002) como uma analogia aplicável à obra que analisaremos neste capítulo. Sobre esse aprimoramento no tratamento do personagem, Candido (2007, p. 61) afirma:

Poderíamos dizer que a revolução sofrida pelo romance no século XVIII constitui numa passagem do enredo complicado com personagem simples, para o enredo simples (coerente, uno) com personagem complicada. O senso da complexidade do personagem, ligado ao da simplificação dos incidentes da narrativa e à unidade relativa de ação, marca o romance moderno, [...] houve na evolução técnica do romance um esforço para com- 
por seres íntegros e coerentes, por meio de fragmentos de percepção e de conhecimento que servem de base à nossa interpretação das pessoas. (CANDIDO, 2007, p. 61)

O romance que nos propomos a analisar encaixa-se nessa categoria de romance moderno por diversos fatores: dentre eles, podemos citar o nível de complexidade do personagem principal, Stephen. Essa complexidade pode ser identificada, corroborando a ideia de Candido (2007), pela forma como interpretamos a maneira como se desenvolve o seu processo de evolução. Ou seja, nossa interpretação sugere que acompanhamos o seu crescimento por meio de trechos narrados da sua vida e esses "fragmentos de percepção" nos levam a criar um retrato coerente da sua personalidade graças à técnica que converge a passagem do tempo na camada linguística do romance de modo a nos aproximar da sua experiência. A importância da evolução do tempo pela camada linguística do romance justifica-se pelo tipo de análise que nos propomos a fazer. Isto é, uma vez que propomos uma análise estrutural da obra, fundamentamo-nos na ideia de que somente através dessa camada de linguagem, daquilo que Genette (1995) chama de "discurso da narrativa", é possível que se acesse a narrativa, enquanto uma realidade construída a partir de ferramentas que são em si, também, linguagem. Como nos lembra Genette (1995, p. 27):

É, portanto, a narrativa, e apenas ela, que aqui nos informa, por um lado, sobre os acontecimentos que relata, e, por outro lado, sobre a atividade que supostamente traz a lume: dito de outro modo, o nosso conhecimento desta e daqueles não pode senão ser indireto, inevitavelmente mediatizado pelo discurso da narrativa, dado que aqueles são o próprio objeto desse discurso e esta deixa aí traços, marcas ou indícios assinaláveis e interpretáveis, tais como a presença de um pronome pessoal na primeira pessoa que denota a identidade da personagem e do narrador, ou a de um verbo no passado que denota anterioridade da ação contada em relação à ação narrativa, sem prejuízo de indicações mais diretas e mais explícitas.

É na estrutura do romance que encontramos a sua conexão direta com o tempo e, portanto, é na camada linguística da narrativa que podemos reconhecer essa relação. A composição da estrutura temporal do romance, como vimos, feita de linguagem, dialoga também com a temática da obra em questão. Veremos um personagem em conflito com os seus desafios de amadurecimento, ou seja, a forma como enfrenta a passagem temática do tempo pela sua vida. Lukács (2007, p. 129) nos lembra ainda que "somente no romance, cuja matéria constitui a necessidade da busca e a incapacidade de encontrar a essência, o tempo está implicado na forma". 


\section{O tempo na linguagem em A portrait of the artist as a young man}

No primeiro capítulo de A portrait, Stephen é apenas uma criança. Logo no trecho inicial do capítulo, Joyce propõe uma tonalidade discursiva que lembra a literatura infantil e é comumente encontrada nos contos de fada e nas narrativas orais. O romance abre essa tonalidade da sua narrativa com a expressão Once upon a time. Podemos interpretar essa escolha para iniciação do romance como uma indicação de que estamos em meio a um universo que alude à infantilidade, aos nuances de uma atmosfera infantil. Essa atmosfera e esse tom são corroborados pela continuidade da narrativa, como se segue:

Once upon a time and a very good time it was there was a moocow coming down along the road and this moocow that was coming down along the road met a nicens little boy named baby tuckoo...

His father told him that story: his father looked at him through a glass: he had a hairy face.

He was baby tuckoo. The moocow came down the road where Betty Byrne lived: she sold lemon platt.

$\mathrm{O}$, the wild rose blossoms

On the little green place.

He sang that song. That was his song.

$O$, the green wothe botheth ${ }^{3}$ (JOYCE, 2001, p. 3).

A primeira impressão que esse trecho nos causa é, certamente, em relação à idade de Stephen. A narrativa propõe para o início da obra uma modulação linguística que se adequa ao primeiro estágio de desenvolvimento da criança. Essa modulação introduz o primeiro aspecto de marcação temporal utilizado por Joyce, a saber, o uso da repetição. No primeiro parágrafo, temos a repetição das expressões moocow e coming down along the road. E logo no segundo parágrafo, temos a repetição do sujeito His father. Podemos inferir a partir dessa primeira ocorrência do recurso da repetição (o que mais adiante será reiterado com outras aplicações do mesmo recurso) que esse momento de abertura do romance nos entrega um referencial de tempo associado com a referida atmosférica tonalidade da infância, uma localização temporal, um ponto de partida, a

3 Era uma vez, e foi muito bom dessa vez que a vaquinha mumu veio descendo a rua e não é que essa vaquinha mumu que vinha descendo a rua me encontra um menino bem fofo chamado Pitoco...

O pai dele contava essa história: o pai olhava para ele por trás de um vidro: tinha a cara cabeluda.

Era ele o Pitoco. A vaquinha mumu descia a rua onde a Betty Byrne morava: ela vendia bala de limão.

Ah, floresce a rosa livre,

No cantinho verdejante.

Ele cantava essa música. Era a música dele.

Ah, folesce a losajante... (JOYCE, 2016, p. 19). 
partir do qual o personagem seguirá o seu processo de evolução. Esse ponto de partida é composto simultaneamente pelo tom infantil e pela repetição no discurso do narrador. Podemos inferir que esse aspecto do seu discurso é influenciado pela idade de Stephen. A repetição sugere uma linguagem simplificada que não caberia necessariamente na voz do narrador, apesar de pertencer a ele e não ao personagem. Mesmo narrando em terceira pessoa, o narrador não deixa de mostrar-se conectado com a subjetividade do personagem. Além da sua utilização das linhas de progressão temporal, temática: quando a narrativa explicitamente nos sugere a idade de Stephen nos termos baby tuckoo e little boy, e estrutural, quando, sem que se declare que se trata da maneira de falar de uma criança, comparamos a forma de cantar no discurso direto do pai, $O$, the wild rose blossoms, e no discurso direto do filho: $O$, the green wothe botheth. Percebemos que Stephen tenta imitar o pai e as palavras parecem distorcer-se em sua forma quando as associamos pela semelhança fonética: rose e wothe, ou ainda blossoms e botheth. Nessa abertura, Joyce localiza o personagem em um tempo a partir do qual a narrativa inicia-se e o leitor dispõe de uma referência de onde parte e desenvolve-se o romance.

O quinto e último capítulo de $A$ portrait direciona-se a alguns aspectos principais no processo contínuo da formação de Stephen e no desenvolvimento da sua experiência temporal. O primeiro aspecto que nos chama a atenção é a questão da relação do personagem com a linguagem. O capítulo inicia-se com Stephen retornando para a universidade, possivelmente estava visitando a família. Nesse ponto, pela relação que ele desenvolve com a família, já podemos notar aspectos da sua evolução pelo ponto de vista da sua mãe. O fato de Stephen não manter muito contato com a família os possibilita enxergar suas mudanças de forma mais evidente. Sua mãe, por exemplo, associa essas mudanças a sua vivência na universidade. Como podemos observar no trecho a seguir:

A second shrill whistle, prolonged angrily, brought one of the girls to the foot of the staircase.

- Yes, father?

- Is your lazy bitch of a brother gone out yet?

- Yes, father.

- Sure?

- Yes, father.

- Hm!

The girl came back, making signs to him to be quick and go out quietly by the back. Stephen laughed and said:

- He has a curious idea of gender if he thinks a bitch is masculine. 
- Ah, it's a scandalous shame for you, Stephen, said his mother, and you'll live to rue the day you set your foot on that place. I know how it has changed you 4 (JOYCE, 2001, p. 135).

Pela perspectiva da sua mãe, a mudança percebida por ela é facilmente associada a universidade, porém, o meio pelo qual ela desperta a sua ideia da mudança de Stephen é pelo uso da palavra bitch. O fato de ter sido pronunciada pelo pai de Stephen não apresenta novidade a sua mãe, porém a naturalidade com a qual ele brinca com o uso da palavra (em inglês, a palavra bitch pode referir-se tanto ao gênero feminino para cachorro, a cadela, como também uma situação desagradável até um significado referente a prostituta) provoca um desconforto nela de modo a comentar que ele ainda se arrependerá de ter ido para aquele lugar, that place, em referência à universidade. A sua percepção de como Stephen está mudado também demonstra um aspecto da sua experiência temporal na narrativa, suas mudanças são resultado de tudo o que ele viveu no tempo em que passou desde o início. A mudança, percebida pela mãe, é consequência do tempo, como ela fala: it has changed you.

O tempo que percebemos quando comparamos o atual estágio de Stephen com a sua época de infância é identificado na narrativa à medida que o personagem se desenvolve. Um aspecto que remete a traços da sua personalidade enquanto criança é a questão de identificar-se como inferior intelectualmente em relação a algum referencial que ele deseja alcançar. No primeiro capítulo, Stephen reflete sobre o seu momento na escola, quanto tempo haveria de passar para que chegasse ao nível dos alunos mais avançados, como no trecho: "It pained him that he did not know well what politics meant and that he did not know where the universe ended. He felt small and weak. When would he be like the fellows in poetry and rhetoric?"5 (JOYCE, 2001, p. 11). Nessa altura da narrativa,

$\overline{4} \quad$ Um segundo assovio agudo, prolongado enfurecidamente, trouxe uma das meninas ao pé da escada.

- O que foi, pai?

- Aquele cadelo vagabundo do seu irmão já saiu?

- Já, pai.

- Certeza?

- Certeza, pai.

$-\mathrm{Hm}$ ! disse:

A menina voltou, fazendo sinais para ele se apressar e sair quietinho pelos fundos. Stephen riu e

- Ele tem uma ideia estranha de gênero se ele acha que cadela é masculino.

- Ah, mas é de morrer de vergonha, Stephen - disse sua mãe -, e você ainda vai se arrepender do dia em que pisou ali. Eu é que sei o quanto você mudou depois (JOYCE, 2016, p. 214).

5 Ele sofria por não saber direito o que significava a política e por não saber onde o universo acabava. Estava se sentindo pequeno e fraco. Quando é que ele seria como os alunos maiores da poesia e da retórica? (JOYCE,2016, p. 30). 
o seu referencial de intelectualidade são os colegas que estão em classes mais avançadas, the fellows in poetry and rhetoric. Atualmente, o referencial de Stephen mostra-se mais avançado tanto em intensidade como em alcance. Esse traço da sua personalidade enquanto criança o fazia querer ser como os seus colegas, entender de política ou dos limites do universo. No seu momento atual, ele reflete sobre o seu papel no espaço de toda a cultura da qual ele faz parte, o seu referencial de intelectualidade são nomes como o poeta romano Horácio (65 a.C 8 a.C), por exemplo. No trecho a seguir, Stephen menciona uma insatisfação que ecoa a mesma personalidade da sua infância, porém em um tempo e estágio de desenvolvimento mais avançado:

[...] it wounded him to think that he would never be but a shy guest at the feast of the world's culture and that the monkish learning, in terms of which he was striving to forge out an esthetic philosophy, was held no higher by the age he lived in than the subtle and curious jargons of heraldry and falconry ${ }^{6}$ (JOYCE, 2001, p. 138).

Como podemos perceber, suas preocupações apresentam-se mais avançadas em relação ao seu momento de criança. Pensar em termos da sua própria estética filosófica o coloca em um tempo diferente daquele do Stephen que se preocupava em aprender o significado de política. Atualmente, Stephen reflete em relação a toda a cultura, the feast of the world's culture. Essa reflexão, no entanto, o incomoda da mesma forma que já o incomodou anteriormente. As palavras, inclusive, mostram-se muito próximas: it pained him e it wounded him, respectivamente para o primeiro e quinto capítulo. Esse procedimento, tanto na questão da preocupação com as palavras nos momentos citados, no primeiro e no quinto capítulo, como também essa questão de se sentir inferior em relação aos seus referenciais de intelectualidade, provoca na estrutura da narrativa uma aproximação com a consciência de Stephen. Quando observamos dois momentos da sua trajetória, percebemos a sua evolução enquanto personagem no processo de aproximar-se dos seus pensamentos, daqueles que compõem a sua personalidade. Nessa aproximação, podemos perceber também a evolução temporal entre um momento e outro através das mudanças sofridas pelo personagem na sua experiência temporal. Na sua análise do romance To the light house, de Virginia Woolf, Auerbach (2002, p. 483) sugere que esse procedimento é característico do romance moderno: "A intenção de aproximação da realidade autênti-

6 [...] Ihe fazia mal pensar que nunca passaria de um hóspede tímido no festim da cultura mundial e que o saber monacal, em cujos termos tentava forjar uma filosofia estética, não era mais considerado nos tempos em que vivia do que os sutis e curiosos jargões da heráldica e da falcoaria (JOYCE, 2016, p. 220). 
ca e objetiva mediante muitas impressões subjetivas, obtidas por diferentes pessoas, em diferentes instantes, é essencial para o processo moderno que estamos considerando". No caso de A portrait, por esse procedimento acima, podemos identificar essa aproximação da realidade, da consciência do personagem. Porém, ela não se dá por meio das impressões de diferentes pessoas, ela dá-se por meio das impressões do mesmo personagem em diferentes etapas da sua vida. Não se trata de personagens diferentes, como podemos ver, Stephen carrega os mesmos traços da sua personalidade, porém, a experiência temporal provoca o efeito de aproximação da sua consciência fazendo com que as impressões sejam apreendidas em tempos diferentes.

Do ponto de vista estrutural, a organização do quinto capítulo é repleta de diálogos. Como podemos perceber, Stephen expressa-se por meio de conversas com seus colegas, seja Cranly, Davin ou Lynch. Sendo uma parte considerável do capítulo dedicada aos diálogos, essa estrutura também afeta a experiência temporal do romance. Quando pensamos a progressão temporal da narrativa durante o diálogo, temos uma noção de imediatismo - pelo fato de os diálogos proporcionarem essa aproximação com o personagem. Ainda que exista a presença do narrador direcionando o diálogo, normalmente com passagens no passado (Stephen said, said the dean ou Cranly turned his pale face to Stephen and said), o momento dos diálogos promove uma diminuição da distância em relação aos personagens, devido ao fato de interagirmos diretamente com suas palavras em discurso direto. Em seu estudo sobre o tempo no romance, Mendilow (1972, p. 124) afirma em relação a nossa percepção temporal: "O romancista moderno usará comumente uma ou mais das três maneiras de enganar a razão do leitor e encorajar sua imaginação a perder-se no tempo: o método dramático, o uso pródigo dos diálogos, e o ponto de visualização restrito". Por definição, "O método dramático é o método da apresentação direta, e visa dar ao leitor a sensação de estar presente, aqui e agora, na cena da ação" (BEACH, 1932, p. 148 apud MENDILOW, 1972, p. 124). Essa sensação pode ser percebida, por exemplo, quando acompanhamos a presença da voz de Stephen por si mesmo ganhar mais espaço, através do contato com as suas próprias palavras, em discurso direto promovendo a aproximação do leitor com o personagem. A presença dessas conversas pode indicar tanto o imediatismo temporal com o qual a narrativa avança como também, tematicamente, esse aumento da voz do próprio personagem em relação também ao narrador. Nesse ponto, estamos mais próximos de Stephen porque podemos ter acesso a algumas de suas impressões diretamente do seu discurso. Em alguns trechos deste capítulo, ainda podemos encontrar uma 
linguagem na qual as palavras do narrador se influenciam pela subjetividade de Stephen, porém a presença constante dos diálogos amplia o alcance da voz do personagem em seu próprio domínio. Em relação à impressão do leitor sobre os diálogos, Mendilow (1972, p. 127) afirma: "O uso pródigo do diálogo é um elemento importante no método dramático, e é talvez o meio mais óbvio de produzir a ilusão do presente e do imediato no leitor".

Ao longo de sua formação de artista, paralela à sua formação pessoal, Stephen vem adquirindo uma qualidade poética ao seu discurso. Seus temas de interesse dividem-se entre a estética filosófica e a poesia. Como a questão da linguagem desenvolve uma intensa presença na forma como ele localiza-se em seu estágio de desenvolvimento atual, a poeticidade do seu discurso também influencia a linguagem pela qual ele se expressa. Essa característica poética do seu discurso corrobora a ideia de que a linguagem evolui paralelamente ao tempo ao longo da narrativa - percebemos esse aspecto pela complexidade atingida nesse estágio da vida do personagem. Observemos o trecho a seguir:

Towards dawn he awoke. O what sweet music! His soul was all dewy wet. Over his limbs in sleep pale cool waves of light had passed. He lay still, as if his soul lay amid cool waters, conscious of faint sweet music. His mind was waking slowly to a tremulous morning knowledge, a morning inspiration. A spirit filled him, pure as the purest water, sweet as dew, moving as music. But how faintly it was inbreathed, how passionlessly, as if the seraphim themselves were breathing upon him!? (JOYCE, 2001, p. 167).

Nesse ponto da narrativa, Stephen acaba de acordar com a inspiração para escrever um poema. O procedimento que encontramos nessa passagem converge a poeticidade temática do personagem com a poeticidade estrutural da narrativa. Da mesma forma que o tempo da sua infância, por exemplo, era localizado na linguagem pelo uso da modulação linguística, esse estágio da sua vida, início da vida adulta, pode ser localizado na linguagem, dentre outras formas, pela complexidade assumida pelo seu discurso. No trecho acima, podemos perceber diversos recursos linguísticos que constroem essa atmosfera poética coerente com o tema da cena. Por exemplo, ele inicia o trecho com uma inversão

7 Perto da aurora ele acordou. Ah, que música mais doce! Sua alma estava toda orvalho e umidade. Por sobre seus membros no sono ondas frescas e claras de luz repassaram. Jazia imóvel, como se jazesse sua alma em meio a frescas águas, consciente de suave música leve. Sua mente despertava lenta para um trêmulo conhecimento matinal, inspiração matinal. Um espírito o preenchia, puro como a mais pura água, doce como orvalho, comovente como música. Mas como se fazia inspirar leve, desapaixonadamente, como se os próprios serafins estivessem respirando sobre ele! (JOYCE, 2016, p. 265). 
dos termos da frase. A frase Towards dawn he awoke sofre uma modificação, pois ao invés de termos uma estrutura convencional na qual o sujeito introduz a frase para ser seguido pelo verbo, por exemplo, He awoke towards dawn, temos uma frase que inverte essa ordem. O efeito produzido por esse recurso é o da criação da poeticidade atmosférica desse trecho. Esse mesmo efeito pode ser percebido no trecho: Over his limbs in sleep pale cool waves of light had passed, no qual, aplicando a mesma ideia, teríamos Pale cool waves of light had passed over his limbs in sleep. Esse recurso é identificado como uma figura de linguagem que pode ser encontrada, por exemplo, na poesia: o hipérbato. Podemos encontrar esse efeito na peça Measure for Measure, de Shakespeare, na citação: "Well, heaven forgive him! and forgive us all! Some rise by sin, and some by virtue fall"8 (SHAKESPEARE, 1994, p. 791). Usando a mesma lógica, à ordem convencional da última frase seria: Some rise by sin, and some fall by virtue. A função desse recurso vai desde ampliar a liberdade do poeta para adaptar a frase à rima ou à métrica, até simplesmente reproduzir a intenção poética associada a essa inversão. No trecho acima em A portrait, percebemos a sua função como uma forma de convergir a temática que permeava a consciência de Stephen, ou seja, a inspiração poética, com a estrutura da linguagem híbrida do narrador no trecho, influenciada por esse momento subjetivo do personagem. Além da questão do hipérbato, podemos identificar também outros recursos que distorcem a linguagem para atingir esse efeito poético, como, por exemplo, outras figuras de linguagem: a prosopopeia, no trecho his mind was walking slowly, que atribui características do personagem à sua mente (na qualidade objeto inanimado); e a sinestesia no trecho: what sweet music, que atribui um registro sensorial ao adjetivo sweet diferente daquele que se adequa ao referencial music. Ou seja, ampliando a apreensão da ideia de música para registros sensoriais de gosto, paladar. O trecho também apresenta algumas metáforas como a associação do corpo de Stephen com o substantivo limbs que pode caracterizar os membros do corpo, mas normalmente refere-se a galhos de uma árvore. Dessa forma, a inspiração que preenche a consciência do personagem, a morning inspiration, atinge a linguagem nessa etapa da sua vida tanto no tema como na estrutura no trecho por meio dos recursos que podemos identificar.

Como podemos perceber, ao comparar o primeiro capítulo da obra com o último o processo de desenvolvimento do personagem fica mais evidente no

8 Bem, que o céu o perdoe, perdoando também, a todos nós! Uns sobem à custa do pecado, outros caem por causa da virtude (SHAKESPEARE, 1978, p. 130). 
sentido de isolarmos dois pontos de sua trajetória e, a partir deles, desenvolver uma visão ampliada da sua formação. O tempo enquanto matéria do romance permite a fluidez da narrativa e, em A portrait, uma das vias por meio da qual acessamos essa fluidez é justamente a via da linguagem, seja a forma como o personagem se expressa em diferentes estágios da sua vida ou ainda sua forma de descrever uma inspiração poética ou como comunica-se com os seus colegas.

\section{Conclusão}

Ao longo de nossa análise, optamos por recortes do primeiro e do último capítulo com o objetivo de tecer um panorama da passagem do tempo em um máximo arco temporal possível. Para tanto, selecionamos trechos dos capítulos mencionado e analisamos a presença do tempo na obra e como essa realidade temporal poderia ser enxergada na linguagem.

A portrait of the artist as a young man, sendo uma narrativa que se propõe a contar a vida de um personagem em seu desenvolvimento pessoal, pode ser interpretado como um romance que se desenvolve na matéria do tempo. Isto é, o tempo torna-se como que um dos seus principais personagens, pois é responsável pela evolução daquele que conduz a história. É através do tempo que Stephen amadurece e, por meio desse amadurecimento, podemos acompanhar a construção dos seus valores, suas ideias, sua personalidade e, principalmente, nos aproximar da sua consciência em formação.

Na nossa análise, discutimos principalmente a forma como o autor modifica a linguagem da obra quando necessário para imprimir uma atmosfera infantil na narrativa, produzindo uma espécie de modulação linguística para localizar o tempo na linguagem. Apresentamos também o conceito de "presente fictício" a partir das considerações de Mendilow (1972).

Um dos aspectos analisados em termos de comparação entre os momentos escolhidos para a análise, ou seja, o início e o fim do romance, foi a questão da relação desenvolvida por Stephen com as suas figuras de superioridade. Quando ainda era uma criança, Stephen comparava-se com os colegas das classes mais avançadas na escola; nos últimos momentos do romance, ele possuía como referencial de intelectualidade grandes autores como Horácio, da tradição latina. Comparamos também as questões da relação de Stephen com sua linguagem poética e a forma como essa linguagem, assim como na sua infância, localizava o seu estágio de desenvolvimento na camada linguística da obra. 
Por fim, apontamos também para alguns aspectos que vão ao encontro das ideias de Auerbach (2002) quando ele propõe uma análise do estilo narrativo de Virgínia Woolf. Percebemos que em A portrait também é possível desenvolver uma aproximação da realidade autêntica do texto, porém, de forma diferente. Ao invés de observar essa aproximação como em To The Lighthouse, sobre a perspectiva subjetiva de mais de um personagem, em Joyce, observamos essa aproximação (o que torna ainda mais possível explorar o tempo na linguagem) por meio de várias impressões subjetivas do mesmo personagem em diferentes momentos de sua vida. Para tanto, concluímos em nossa análise que em A portrait, como podemos perceber, o tempo passa, em meio a várias camadas, também pela linguagem da obra.

\section{Referências}

AUERBACH, E. A meia marrom. In: AUERBACH, E. Mímesis. São Paulo: Perspectiva, 2002. p. 471498.

BAKHTIN, M. Epos e romance: Sobre a metodologia do estudo do romance. In: BAKHTIN, M. Questões de literatura e de estética: a teoria do romance. São Paulo: Hucitec, 2010. p. 397-428.

Fragmentos dos anos 1970-1971. In: BAKHTIN, M. Notas sobre literatura, cultura e ciências humanas. São Paulo: Editora 34, 2017. p. 21-56.

BENJAMIN, W. O narrador: Considerações sobre a obra de Nikolai Leskov. In: BENJAMIN, W. Obras escolhidas: Magia e técnica, arte e política. São Paulo: Brasiliense, 2011. p. 197- 221.

CANDIDO, A. A personagem do romance. In: GUINSBURG, J. (Org.). A personagem de ficção. São Paulo: Perspectiva, 2007. p. 51-80.

GALLO, R. A. G. Considerações acerca da concepção de romance nos escritos "A teoria do romance" (1914-15) e "O romance como epopeia burguesa" (1935) de Georg Lukács. Revista do Seta, Campinas, v. 6, p. 376-390, 2012.

GENETTE, G. Discurso da narrativa. Trad. Fernando Cabral Martins. Lisboa: Vega, 1995.

JOYCE, J. A portrait of the artist as a young man. Ware, Hertforshire: Wordsworth Classics, 2001.

Um retrato do artista quando jovem. Trad. Caetano W. Galindo. São Paulo: Penguin Classics Companhia das Letras, 2016.

LUKÁCS, G. A Teoria do Romance. Trad. José Marcos Mariani de Macedo. São Paulo: 34, 2007. $240 \mathrm{p}$.

MENDILOW, A. A. O tempo e o romance. Trad. Flávio Wolf. Porto Alegre: Globo, 1972. 272 p.

MENDONÇA JUNIOR, J. W. O tempo do artista em A portrait of the artist as a young man. Dissertação (Mestrado em estudos da linguagem) - Centro de Ciências Humanas, Letras e Artes, Universidade Federal do Rio Grande do Norte, Natal, 2018. 
MOISÉS, M. Dicionário de termos literários. 12. ed. São Paulo: Cultrix, 2004.

MORETTI, F. Da evolução literária. In: MORETTI, F. Signos e estilos da modernidade: ensaio sobre a sociologia das formas literárias. Rio de Janeiro: Civilização brasileira, 2007. p. 309-327.

RICOEUR, P. A experiência temporal fictícia. In: RICOEUR, P. Tempo e narrativa II. Campinas SP: Papirus, 1995.

ROSENFELD, A. Reflexões sobre o romance moderno. In: ROSENFELD, A. Texto/Contexto I. São Paulo: Perspectiva, 1996. p. 75-97.

SHAKESPEARE, W. Measure for measure. In: SHAKESPEARE, W. The Complete Works of William Shakespeare. New York: Barnes \& Noble, 1994.

Medida por Medida. In: SHAKESPEARE, W. Shakespeare comédias sonetos. São Paulo: Abril Cultural, 1978.

\section{Sobre os autores}

Jorge Witt de Mendonça Junior - Doutorando na Universidade Federal do Rio Grande do Norte (UFRN), Centro de Ciências Humanas, Letras e Artes, Natal RN, e-mail: witt. junior@gmail.com, Lattes: http://lattes.cnpq.br/2898085665802634, Orcid: https://orcid. org/0000-0002-9600-4967.

Rosanne Bezerra de Araujo - Doutora pela Universidade Federal da Paraíba (UFPB) e professora na Universidade Federal do Rio Grande do Norte (UFRN), Centro de Ciências Humanas, Letras e Artes, Natal RN, e-mail: rosanne.araujo@terra.com.br, Lattes: http:// lattes.cn pq.br/7328556088478313, Orcid: https://orcid.org/0000-0003-4308-3881. 